\title{
Brain, Body and Culture: A Biocultural Theory of Religion ${ }^{1}$
}

\author{
Armin W. Geertz \\ Religion, Cognition and Culture Research Unit (RCC), Department of the Study of Religion, \\ Aarhus University, Denmark \\ AWG@teo.au.dk
}

\begin{abstract}
This essay sketches out a biocultural theory of religion which is based on an expanded view of cognition that is anchored in brain and body (embrained and embodied), deeply dependent on culture (enculturated) and extended and distributed beyond the borders of individual brains. Such an approach uniquely accommodates contemporary cultural and neurobiological sciences. Since the challenge that the study of religion faces, in my opinion, is at the interstices of these sciences, I have tried to develop a theory of religion which acknowledges the fact. My hope is that the theory can be of use to scholars of religion and be submitted to further hypotheses and tests by cognitive scientists.
\end{abstract}

Keywords

biocultural theory, embrainment, embodiment, enculturation, extended mind, distributed cognition, neuroscience, religion

\section{Introduction}

At the Religion, Cognition and Culture Research Unit (RCC) in Aarhus, our central axiom is that cognition is not just what goes on in the individual mind. In adapting our approach to contemporary research in neurobiology, archaeology, anthropology, comparative religion and philosophy of science, we hold that cognition is embrained, embodied, encultured, extended and distributed. ${ }^{2}$

\footnotetext{
${ }^{1}$ My warmest thanks are extended to Michael Stausberg, Jesper Sørensen, Jeppe Sinding Jensen and Aaron Hughes for comments and critiques of earlier drafts of this paper. Although I feel that their insights have helped improve the article, the result is my responsibility alone. This article is a result of cooperation between the MINDLab UNIK initiative at Aarhus University, funded by the Danish Ministry of Science, Technology and Innovation, and the Religion, Cognition and Culture Research Unit (RCC) at the Department of the Study of Religion, Aarhus University.

2 Geertz 2004 \& 2008, Jensen 2002 \& 2009, Sørensen 2004.
} 
Although this probably makes sense to most scholars in the humanities, it is not without its drawbacks. The mentalistic cognitive science approach, which we criticize, is simplified enough to subject itself to hypotheses and experiments. Our approach, on the other hand, is much like life in general: a jumble of factors almost impossible to tease out into analytically meaningful units, theories and hypotheses. Analyzing minds without bodies and culture hardly makes any sense, but how should we go about basing a theory of religion grounded in our understanding of cognition that not only makes sense but is also available to further theories, hypotheses and tests? There are fortunately a growing number of experimental scientists who are providing us with relevant, testable theories and hypotheses. These results can, or at least should, be applicable to the comparative study of religion which in practice draws on a wide variety of disciplines. We should therefore also be able to accommodate the methods and insights of recent hybrid cognitive sciences such as social neuroscience, cultural neuroscience, cognitive anthropology, cognitive archaeology, the cognitive science of religion and neuroanthropology.

Three concepts need clarification. The definitions provided here are neither definitive nor systematically argued. They are my points of departure and serve as well to indicate what they might mean in some of the studies mentioned here.

I have elsewhere argued that "religion" should be understood as "a cultural system and a social institution that governs and promotes ideal interpretations of existence and ideal praxis with reference to postulated transempirical powers or beings" (Geertz 1999: 471). The point here is that religion consists of ideas and actions guided by certain principles or beliefs. I do not consider religion to be qualitatively different than any other cultural system or social institution. Therefore, psychological and neurological studies of cultural phenomena are applicable to religion as well, and this assumption therefore will not be argued further.

The second concept central to this paper is "culture." Culture, according to anthropologist Clifford Geertz, is the "webs of significance" that humans spin for themselves (C. Geertz 1973: 5). Taking a basically semiotic approach, Geertz understands culture as consisting of systems of symbols and meanings (C. Geertz 1973: 17). Psychologists understand culture from a more cognitive point of view, with which I believe Clifford Geertz would not entirely have agreed. However, neuropsychologist Merlin Donald's understanding of culture is very close to Geertz's:

The word "culture" usually connotes something other than its cognitive aspect. It usually refers to a set of shared habits, languages, or customs that define a population of people. It may be these things, but on a deeper level, any given culture 
is a gigantic cognitive web, defining and constraining the parameters of memory, knowledge, and thought in its members, both as individuals and as a group. (Donald 2001: xiv)

Such definitions of culture seem to ignore its material aspects, but material culture is assumed and discussed by both Geertz and Donald. I have given material culture a more explicit role in the theory proposed in this paper.

As for the term "biocultural," I take it to refer to the fact that humans are simultaneously biological and cultural creatures. The term does not mean that cultural features are biological or that biological features are cultural. The complex issues of causality involved in the theories discussed below will not be resolved here. I use the term simply to mean that we are hybrid creatures uniquely situated in biological and cultural systems on more or less equal terms.

Since the expanded view of cognition assumed in this paper is unwieldy, I will break it down into its component parts. These are: 1) the body and the brain, 2) minds, 3) culture and society. There are exciting studies on each component which I feel are relevant for theories of religion. It would be herculean, however, to provide all the latest references. I will, therefore, restrict my discussion to recent work by cutting-edge neurologists, psychologists and others that will help me lay the groundwork for a biocultural theory of religion.

\section{The Body and the Brain}

The brain is not an isolated organ. It is embodied in a body through an intricate nervous system, divided into a number of subsystems, which it more or less controls. These systems are coordinated by neural maps in the brain, and one of them, the autonomic system, originates in deeper parts of the brain near the pituitary gland and regulates homeostasis through two subsystems: the sympathetic and the parasympathetic. These systems allow bodily states to be influenced by both internal and external stimuli.

This network of subsystems functions as a whole, connecting outside and inside in an apparently seamless entity which, furthermore, is connected to both our limbic system and executive control system. The limbic system is our emotional center, ${ }^{3}$ and the executive control system, located in the prefrontal cortex, is where higher cognitive functions and senses of self occur.

\footnotetext{
${ }^{3}$ Neurologists are not in agreement about what the limbic system is. Many simply refer to the "emotional brain."
} 
The fact that these two crucial areas are intimately bound to the nervous system, hormonal system and the body's homeostatic regulation means that all of these aspects, i.e. bodily processes and stimuli, emotions and feelings, higher order cognition, etc. are connected. Thus, the whole complex system can be affected by different means at any point in the system. For instance, our mental states or feelings can influence the homeostatic balance of the body. On the other hand, and more significantly for the study of religion, the physical manipulation of body posture can influence our emotional and mental states (Barsalou et al. 2003, Niedenthal et al. 2005).

This interactive system can serve as a powerful tool in the hands of people who know how to use it. A consequence of this fact is that people who manipulate our nervous system (for instance by therapeutic massage or ritual violence) can expose our minds and brains to their ideas, values and desires. We are not blank slates, of course, but we are hyper-social creatures, eager to connect with and to please others. The complex mechanisms of somatic and psychological manipulations are quite often inaccessible to our conscious attention and, therefore, can have greater impact than we realize. This together with our sociality make us surprisingly vulnerable to manipulation.

Rituals are one of the most dramatic ways to manipulate bodily and mental states and thus change and direct our minds. Techniques that are often used to manipulate bodies are:

- song, dance, clapping, swaying, jumping in place, hopping;

- diverse body postures such as bowing, strutting, prostration;

- other techniques such as torture and violence in initiation rituals, vision rituals, and mysticism rituals;

- use of specific techniques for changing mental states such as smoking, alcohol, drugs, fasting, extreme movement or immobility, and photic and sonic drive techniques.

Music and rhythmic movement are extremely seductive methods (Brown \& Volgsten 2006). They are clearly connected to early interactions between mother and child, involving stereotypy (simplification, formalization), repetition, exaggeration and elaboration, traits which in more expanded form are central to religious rituals (Dissanayake 1992 \& 2000). Thus ceremonies involving such techniques tug deeply at the psychological and somatic foundations of each and every individual and have the ability to arouse, shape and form emotions and mental states, thus allowing the transfer and sharing of norms and ideals. 
Neurologist Lawrence Barsalou and his team have in an article entitled "Embodiment in religious knowledge" tried to demonstrate what kinds of techniques are involved (Barsalou et al. 2005). There are three main ways in which embodiment is at play: in religious visions, religious beliefs and religious rituals:

In religious visions, the process of simulation offers a natural account of how these experiences are produced. In religious beliefs, knowledge about the body and the environment are typically central in religious frameworks, and are likely to affect the perception of daily experience. In religious rituals, embodiments appear central to conveying religious ideas metaphorically and to establishing them in memory (Barsalou et al. 2005: 14).

More work needs to be done in this area. How do religions use the body in conveying knowledge, implementing values and producing or changing mental and emotional states? What kinds of activities and attitudes are at play, for instance, in relation to the senses (Ackerman 1990, Classen 2005)?

Another area where embodiment and religion meet is in traditional healing systems. These systems and techniques are firmly anchored in various religious worldviews. By "traditional healing systems," I do not only mean those of indigenous or tribal religions. From evangelical laying on of hands, ancient Babylonian dentistry, drinking dissolved parchment fragments from the Qu'ran to full-blown shamanistic séances, all of them combine (religious) rituals with narrative therapy, suggestion and physical modulation or manipulation of the body that can result in subsequent somatic and cognitive effects (Frank 1974). A key factor in such techniques is placebo, which until recently was considered by medical researchers to be an irritating confounding factor. Recent research, however, has focused on the neurology and physiology of the placebo effect. Physician Ted J. Kaptchuk argues that there are various ways that the placebo effect is stimulated in alternative healing rituals. In fact, he defines such rituals as "placebo dramas," i.e. placebo-generating health care systems that thrive on performative efficacy which in turn relies on "the power of belief, imagination, symbols, meaning, expectation, persuasion, and selfrelationship" (Kaptchuk 2002: 817-818). ${ }^{4}$ I suggest that most traditional healing systems are also placebo dramas.

Thus, in terms of a biocultural theory of religion, embrainment and embodiment are key factors. This means that cognition functions in the context of embodied brains.

\footnotetext{
${ }^{4}$ See Csordas 2002, Evans 2003, Petrovic et al. $2002 \& 2005$ and Sterzer et al. 2008.
} 


\section{Minds}

As mentioned in the introduction, our cognition involves a great deal of activity outside of individual brains. In the following, I will explore how this works. Recent work on situated cognition indicates that cognition is distributed and extended as well as embodied. What is meant by distributed and extended is that our cognition "routinely exploits structure in the natural and social environment (the embedding thesis)" and it extends "beyond the boundaries of individual organisms (the extension thesis)" (Robbins \& Aydede 2009: 3). This line of research was pioneered by anthropologist Edwin Hutchins (Hutchins 1995) and philosophers Andy Clark (Clark 1997, 2008) and Mark Rowlands (Rowlands 2003). A further aspect is the phenomenon of material anchoring that is prominent in cognitive archaeology. This branch of research examines how material objects and symbols serve as cognitive anchors for the mind (Malafouris 2010, Mithen 1996, Renfrew \& Scarre 1998, Wilson 2010). This approach is still being developed, but there are several explanations of precisely how material objects and symbols serve as anchors of the mind which I will discuss in the following.

Objects are regularly used to symbolize other things, especially intangible concepts and symbols in, for instance, religious cosmologies. Cognitive archaeologist Steven Mithen has even argued that religious ideas and institutions could not have become established until humans produced material symbols (Mithen 1999: 148). He claimed that religious ideas are difficult to conceive, but once they take material shape, they become much easier to communicate and to pass on from generation to generation (Mithen 1999: 164). I take issue with his claim that religion first appeared only when clearly identifiable, material religious symbols appeared-his claim is mainly on methodological grounds-but there is no doubt that material symbols provide us with external storage. Cognitive archaeologist Colin Renfrew argues that most social life "is mediated by human interactions with things," and, further, that "the world in which most of us live today is an artefact" (Renfrew 1998: 1). Again, this strikes me as being an exaggeration, but I agree with him that "material culture is not only reflective of social relations and of cognitive categories: it is to a large extent constitutive of these also" (Renfrew 1998: 3).

Cognitive archaeologist Lambros Malafouris has provided a useful catalogue of how artefacts are constitutive in cognition in terms of what he calls the "brain-artefact interface (BAI)" (Malafouris 2010: 265). He argues that there are three major interrelated categories: mediational, temporal and plastic. His working assumption is: 
that the functional structure and anatomy of the human brain is a dynamic construct remodeled in detail by behaviourally important experiences which are mediated, and often constituted, by the use of material objects and cultural artefacts which for that reason should be seen as continuous integral parts of the human cognitive architecture (Malafouris 2010: 266).

Psychologist Margaret Wilson understands culture in broader terms than cognitive archaeologists do. She argues that culture in general "re-engineers cognition" during ontogenetic development. She is not simply claiming that culture influences the contents of cognition, she is claiming that it alters the how of cognition, in other words "the mechanisms by which cognitive tasks are accomplished" (Wilson 2010: 180-181). In fact, she points out that it is a life-long process which constitutes what she calls "cognitive re-tooling." The kinds of tools she has in mind are not only the physical tools that archaeologists are concerned with, but also other kinds of tools such as number representation, spatial representations of time, maps, writing and literacy, musical literacy and musical cognition (Wilson 2010: 181-182).

Most cognitive re-tooling is grounded in embodied cognition, i.e. "the use of perceptual, motor and spatial representations - representations of the body and the physical world-to facilitate cognition" (Wilson 2010: 184). In this Wilson draws on the work of Barsalou (2005), Gallese \& Lakoff (2005) and Zwaan \& Taylor (2006) in which sensorimotor simulations are used to represent abstract concepts and relationships "by way of analogical mappings" (Wilson 2010: 184). Her prediction is that the brain's somatic and sensory mappings constrain cognitive retooling (Wilson 2010: 184). Much like Merlin Donald's evolutionary account (see the next section), Wilson claims that flexible, voluntary control over the body permitted the emergence of cognitive re-tooling (Wilson 2010: 185). ${ }^{5}$

Scholar of religion Matthew Day has explored the relationships between religion, cognition and the extended mind. He argues that "the broad spectrum of rituals, music, relics, scriptures, statues and buildings typically associated with religious traditions" are not just cultural wrappings but are central cognitive components (Day 2004: 101). We surround ourselves, he notes in reference to Donald Norman, with "things that make us smart" (Norman 1993, Day 2004: 112). We surround ourselves with tools of all sorts that help confer intelligence and move us beyond the natural boundaries of our biological brains. Thus in proposing a supplementary interpretation of religious rituals

${ }^{5}$ We do not yet know how such a process works. Neurologists Stanislas Dehaene and Laurent Cohen have posited a "neuronal recycling hypothesis" according to which "cultural inventions [they are specifically referring to reading and arithmetic] invade evolutionarily older brain circuits and inherit many of their structural constraints" (Dehaene \& Cohen 2007: 384). 
to those of Lawson, McCauley and Whitehouse, Day contends that religious rituals can be mind tools "that functionally extend the bare Darwinian brain's aptitudes" (Day 2004: 114).

Thus, in terms of a biocultural theory of religion, extension and situatedness are key factors. A constitutive instrument in the extension of mind are the tools of all sorts that assist us in a variety of ways to harness fleeting ideas and to function effectively in cognitive networks.

\section{Culture and Society}

Cognition is also distributed. It is inextricably enmeshed in emotional and semantic networks. The distributed quality of cognition developed during hominin evolution, and it must be stimulated in specific ways in each and every individual's early development.

The way that minds draw on collective emotional and semantic networks is through what Merlin Donald calls cognitive governance systems. With the latter, Donald was referring to how the evolutionary development of the prefrontal cortex led to a top-down cognitive governance system in the brain which allowed for control over the body and the development of mind. This path-breaking ability resulted in the apparently seamless somatic system, mentioned above, which connects higher cognitive functions with emotions and the body.

In Donald's biocultural theory, the biological brain at some point in history (long before the appearance of Homo sapiens), driven by its growing capacity to become embedded in cognitive communities, increased the precision of communication and the distributed activity of many brains through culture, and, ultimately, led to symbolic thought and language (Donald 2001: 252-253). The demands of a "community of brains" provided the needed selective pressures. "Enculturation," Donald argues, "dominates human cognitive development" (Donald 2001: 254).

According to Donald, the hominin line has gone through four evolutionary stages: the episodic, mimetic, mythic and theoretic (Donald 2001: 259262). The episodic, which we share with other primates, is based on self-in-event-sensitivity. It is episodic and reactive. With the growth of the cortex and the subsequent top-down control over the body, a stage that lasted from 2 million to 400,000 years ago, early hominids developed mimetic behavior. This ability, based on skill, gesture, mime and imitation, led to the creation of cultural styles and conventions such as "ritualized, socially coordinated public behaviors" (Donald 1999: 22). The mimetic abilities of 
re-enacting or "ritualized patterns," Donald claims, is the primordial source of "our communal cultural traditions" involving tool-making, food styles, hunting, subsistence patterns, and so on (Donald 1999: 22-23).

The third stage, the mythic, coincides with the development of language in archaic Homo sapiens. In this stage, oral traditions radically enhanced the capacity for cultural traditions:

These traditions may be viewed as gigantic representational conventions that summarize the accumulated wisdom of a people. Such narratives were a great leap from the older framework of simpler ritualized behaviors that had been put in place by mimesis, and served as a kind of collective governor of values, beliefs, and behavior for every member of the society (Donald 1999: 23).

The fourth stage, the theoretic, began when we started using symbols and various material artefacts as external memory and data banks. This stage, although ancient (perhaps going back to 70,000 years ago), became immensely powerful with the invention of writing. Writing and other symbolic systems allowed us to collect, formalize, analyze and systematize massive external storage banks.

We are hybrid creatures, consisting of biology and culture. Human minds are deeply enculturated in cognitive networks. These networks help each individual mind gain control over his or her life and functions, but, at the same time, these networks also have a great deal of control over each individual mind. Thus, in Donald's view, cultural systems are also collective governance systems, or, as he also terms it, "governing hierarchies." And religion, he claims, is probably the most powerful governance system ever developed.

Cognitive governance systems are used to gain access to individual and collective minds and influence the way they see the world and each other. Learning how to attune oneself to these systems is the basic bread and butter of socialization. The latter involves specific techniques to interlink the infant's attentional system with those of others (Donald 2001: 255). These techniques are universal and involve a range of facial, bodily, sonic and linguistic manipulations meant to entice the child into the intricate web of the cultural scaffolding system. The point is not to download the system-no one can do this - rather to gain competence in using the cultural matrix. This learning process is transmitted through pedagogy, generation after generation, which gives the child the ability to maneuver the labyrinths of cultural meaning. As Donald argues, any nuance of gaze, gesture, tone of voice or facial expression is pregnant with meaning (Donald 2001: 256). Thus, the earliest socialization techniques are important aspects for the study of religion, including styles of nursing (Yovsi 2003, Hrydy 2009), touch, gaze and so on. These psychological techniques stimulate basic human abilities such as moral sensibility (Sinnott-Armstrong 2008), social intelligence (Blakemore \& Frith 
2005, Raafat et al. 2009, Vogeley \& Roepstorff 2009), mindsight (Gallagher \& Frith 2003, Gallagher et al. 2000, Humphrey 1986: 94) and filling the “information gap" (C. Geertz 1966: 50).

Narratives take on a particular significance in the context of Donald's theory because they become crucial instruments in constructing gender, identities, selves, groups, nations and others. In other words, the virtual worlds of religions and cultures become transformed into human, social realities (Donald 2001: 295ff., Plotkin 2002, Roepstorff et al. 2009). There is much to be gained in rethinking narrative from a biocultural perspective. ${ }^{6}$ Religious narratives are not just stories about counterintuitive agents. They are visceral, salient, social and cultural events. Narratives are at the base of the world models that govern every individual directly or indirectly (Donald 2001: 324ff.). They help us coordinate our biological, psychological, social and cosmological maps.

Thus, in terms of a biocultural theory of religion, distribution and enculturation are key factors. Cognition is distributed in networks of feelings, memories and knowledge. The mechanism that is inimical to this ability is deep enculturation, driven by the communicative needs of communities of brains.

\section{A Biocultural Theory of Religion}

What I envision is a combination of theories from neurobiology, social psychology, anthropology, cognitive science, archaeology and comparative religion. I am convinced that nothing less can do the job and am therefore arguing that traditional disciplinary boundaries are in need of modification and change. The term "biocultural theory of religion" may strike some as too much hard science, but I hope that I have shown that the intimate interrelations between body, brain, culture and society, demand a "biocultural turn." This theory draws inspiration obviously from Merlin Donald, but also from Terrence Deacon's biosemiotic theory (Deacon 1997). The latter is not just about understanding biology as systems of signs, which many biosemioticians do, but, more importantly, understanding humans as biological and semiotic creatures, thus combining linguistic theory with neurobiology. ${ }^{7}$

\footnotetext{
6 See the coming volume on Religious Narrative, Cognition and Culture, edited by Geertz \& Jensen (2010). See also Bruner \& Haste 1987, Cozolino 2002, Edwards 1997, Herman 2003, Hogan 2003, Nair 2002, Neisser \& Fivush 1994, Neisser \& Jopling 1997, Ochs \& Capps 1996 \& 2001, Peacock \& Holland 1993, Siegel 1999 \& 2001, Rosengren et al. 2000 and Sarbin 1986.

${ }^{7}$ Neurologist Denis Mareschal and colleagues have attempted a similar synthesis on more general terms from a neurological perspective (Mareschal et al. 2007, vol. 1 \& 2).
} 
What, then, should a biocultural theory of religion consist of, and what should it be able to account for? In answering this, I slightly expand on Jeppe Sinding Jensen's typology (Jensen 2003: 124-125). He is concerned with "modes of comparison," of which, he argues, there are four: form, function, structure and meaning. I suggest that these four together with origin can conveniently serve as five aspects that any theory of religion must deal with. ${ }^{8}$ Jensen argues, furthermore, that his modes work across three "levels of reality": the sociological, cognitive and semantic-semiotic levels. In line with my argument in this essay, I suggest that we add one more level of reality, namely, the neurobiological. Thus, I am proposing a matrix of five aspects (origin, form, function, structure, meaning) on four levels of reality (neurobiological, cognitive-psychological, sociological, semantic-semiotic).

One of the points of this essay is that we need to pay more attention to the neurobiology of religion and culture. We are, as argued, not just mental creatures, but, perhaps even more so, somatic creatures. When confronted with religious claims and behaviors, we must not only think of the semantic, sociological and psychological aspects but also the neurological and somatic aspects. The latter are very real and are deeply involved in all other so-called "higher" cognitive functions (Johnson 2007). Thus it makes good sense to distinguish the neurobiological as a level in its own right-even as the fundament of all other levels.

The conjunctions of these aspects and levels are expressions of emergent systems. Thus, in agreement with anthropologist Roy Ellen, the theory presented here assumes "nested levels of explanation" (Ellen 2010: 387). The biocultural theory presented here is a general framework for more precise "conjunctive" theories and hypotheses.

The table below is exploratory. It is a model of analytical units (one might also call them conjunctive nests or emergent systems) within a general biocultural theory of religion framework. It is not possible in an essay of this kind to expand on the implications and, more importantly, the applications of the theory and its units. My only concern here is to sketch out what I have in mind. The units in the table are hierarchical, but the table can be read from top to bottom, bottom to top and horizontally back and forth. In the following, I will discuss the units from left to right and top down.

Beginning with the first column on origins of religion, there are already a large number of cognitive theories on that topic. ${ }^{9}$ However, the differences

8 This meshes well with Michael Stausberg's list of main questions for theories of religion: the specificity, origins, functions and structures of religion(s) (Stausberg 2009: 3-6).

9 See for instance Bulbulia 2004, Feierman 2009, Geertz 2011, Schloss \& Murray 2009 and Whitehouse \& Martin 2004. 
between the theories follow along the same fissure lines as already described between a biocultural theory and a mentalistic cognitive theory. A biocultural theory would have to account for how and, if possible, when the mind became enculturated. As for the when, an obvious point of entry would coincide with the appearance of stone tools which evidence also indicates coincided with the expansion of the brain. As for the why, much work still needs to be done on the relationship between the growth of the brain and the appearance of culture. If we could account for exactly what happened, then I think we could account for the other four aspects without much further ado. That is why I believe that current theorizing on the origins of religion are extremely important for the entire comparative study of religion enterprise. It would seem, at least, that brain expansion allowed cognitive governance and the ability to deal more precisely and effectively in collective actions, in other words, social governance. And the ultimate goal of an increase in our semantic and semiotic abilities is to increase the effectiveness of communication.

In terms of the forms of religion, the most obvious characteristics are found in their material forms. Theories of materiality and material anchors come into play here. How do tools anchor our bodies and minds? What are the salient features (or, following Boyer, gadgets) that catch hold of our minds, bodies and brains? Material culture includes texts, books, costumes, masks, temples, natural objects, all of which are used to materially express symbolic ideas and worlds.

Table 1. Five theoretical aspects at four levels of reality

\begin{tabular}{|c|c|c|c|c|c|}
\hline \multirow[b]{2}{*}{ Levels } & \multicolumn{5}{|c|}{ Aspects } \\
\hline & Origin & Form & Function & Structure & Meaning \\
\hline $\begin{array}{l}\text { Neuro- } \\
\text { biological }\end{array}$ & Brain expansion & $\begin{array}{l}\text { Anchoring } \\
\text { processes }\end{array}$ & $\begin{array}{l}\text { Brain-body } \\
\text { manipulations }\end{array}$ & $\begin{array}{l}\text { Brain-culture } \\
\text { interface }\end{array}$ & $\begin{array}{l}\text { Somatic- } \\
\text { neurological } \\
\text { schemata }\end{array}$ \\
\hline $\begin{array}{l}\text { Cognitive- } \\
\text { psychological }\end{array}$ & $\begin{array}{l}\text { Cognitive } \\
\text { governance }\end{array}$ & $\begin{array}{l}\text { Cognitive } \\
\text { tools }\end{array}$ & $\begin{array}{l}\text { Emotional } \\
\text { motivations }\end{array}$ & $\begin{array}{l}\text { Cognitive } \\
\text { networks }\end{array}$ & $\begin{array}{l}\text { Cognitive- } \\
\text { psychological } \\
\text { schemata }\end{array}$ \\
\hline Sociological & Social governance & $\begin{array}{l}\text { Material } \\
\text { culture }\end{array}$ & Actions & $\begin{array}{l}\text { Systems and } \\
\text { institutions }\end{array}$ & $\begin{array}{l}\text { Sociological- } \\
\text { political- } \\
\text { economic } \\
\text { schemata }\end{array}$ \\
\hline $\begin{array}{l}\text { Semantic- } \\
\text { semiotic }\end{array}$ & Communication & $\begin{array}{l}\text { Material } \\
\text { symbols }\end{array}$ & Justifications & $\begin{array}{l}\text { Cosmologies } \\
\text { and } \\
\text { worldviews }\end{array}$ & $\begin{array}{l}\text { Symbolic- } \\
\text { discursive } \\
\text { schemata }\end{array}$ \\
\hline
\end{tabular}


Jensen understands "function" to mean "the properties, rules, and relations among things and which order things, both logically and causally" (Jensen 2003: 125). In other words, functions imply causal interdependence between elements. In sociological terms, function is the causal roles that institutions and actions in society play. In terms of the functions that religion might have at various levels of reality, it is evident that there is a great deal of brain-body manipulation at play which ultimately is meant to emotionally motivate individuals cognitively and psychologically. In social terms, religion inhibits or encourages actions and in semantic-semiotic terms, a great deal of semantic energy is devoted to justifying those actions and beliefs.

In terms of the structures of religion, which Jensen describes as the "systems of relations and rules, on the architectures of worlds, cosmologies, patterns in and of action complexes, socio-cultural institutions" (Jensen 2003: 125), what such relations might be at the neurobiological level is difficult to say. Drawing on the above-mentioned brain-artefact interface argued by Lambros Malafouris, I would suggest that what is at play is a broader brainculture interface. An interface in Malafouris view is anything that effectuates communication and interaction between processes. He is primarily thinking of technological mediations "that enable the configuration of a dynamic alignment or tuning between neural and cultural plasticity" (Malafouris 2010: 265). I am thinking of material and non-material tools and gadgets that connect mind, brain and body in systematic ways. At the psychological level, there are cognitive network structures into which all humans are socialized which provide the individual with group alignment processes. These networks are an expression of social systems and institutions, which again are embedded in cosmologies and worldviews.

Jensen takes on the difficult issue of meaning to mean how religious worlds are articulated, but more importantly how they formalize systems of knowledge into schemata which serve as meaningful frameworks for action and knowledge. ${ }^{10}$ To his list of schemata (social-political-economical-practical; smbolic-discursive-linguistic-axiological; cognitive-psychological-epistemological) (Jensen 2003: 125), I have added the somatic-neurological schemata which our brains have as neural maps in the sensory-motor cortex and other areas. I consider the schemata of the four levels to constitute maps to live by, and I understand religion as more or less systematic attempts to transform maps into territory, or to use Clifford Geertz terminology the fusing of models of and models for reality.

${ }^{10}$ For similar arguments, see Christina Bicchieri 2006. 


\section{Conclusion}

Whether the theory proposed here can be of use to scholars of religion and be submitted to further hypotheses and tests by neuropsychologists and cognitive scientists remains to be seen. The most important point of this essay is that we need to take the concepts of embrainment, embodiment, enculturation, extension and distribution very seriously if we wish to develop theories and explanations of human worlds. Furthermore, we need not only to open the historical and textual dimensions of our work to the neurobiological and psychological dimensions, but also to show our colleagues in the cognitive sciences that any theory of human cognition must deal with the power, formative impact and constitutive role that culture plays. Religion is one of the most powerful cultural institutions ever created by sapient minds. It not only helped us escape the solipsism of our individual minds but also to control and shape the matrices within which our minds are located. The vast biocultural complexity within which our minds develop and grow must be in the forefront of any general theory of religion.

Although much has already been discovered, we still do not know the exact details of how cultures and brains work together. One of the reasons for this is that neuroscientists need input and cooperation from cultural scientists. Thus, a challenge has been laid at our doorstep. Do we need a further invitation?

\section{References}

Ackerman, Diane (1990). A Natural History of the Senses. New York: Random House, Inc., 1990; reprint, New York: Vintage Books Edition, 1995.

Barsalou, Lawrence W. (2005). Abstraction as dynamic interpretation in perceptual symbol systems. In Building Object Categories in Developmental Time, edited by L. Gershkof-Stowe \& D. K. Rakison: 389-431. Mahwah: Lawrence Erlbaum Associates.

Barsalou, Lawrence W., Aron K. Barbey, W. Kyle Simmons \& Ava Santos (2005). Embodiment in religious knowledge. Journal of Cognition and Culture 5 (1/2): 14-57.

Barsalou, Lawrence W., Paula M. Niedenthal, Aron K. Barbey \& Jennifer A. Ruppert (2003). Social embodiment. The Psychology of Learning and Motivation. Advances in Research and Theory 43: 43-92.

Bicchieri, Cristina (2006). The Grammar of Society: The Nature and Dynamics of Social Norms. Cambridge \& New York: Cambridge University Press.

Blakemore, Sarah-Jayne \& Uta Frith (2005). The Learning Brain: Lessons for Education. Oxford, Malden, Victoria: Blackwell Publishing.

Brown, Steven \& Ulrik Volgsten, eds. (2006). Music and Manipulation: On the Social Uses and Social Control of Music. New York: Berghahn Books.

Bruner, Jerome \& Helen Haste, eds. (1987). Making Sense: The Child's Construction of the World. London \& New York: Methuen \& Co. Ltd. 
Bulbulia, Joseph (2004). The cognitive and evolutionary psychology of religion. Biology and Philosophy 19: 655-86.

Cacioppo, John T. et al., eds. (2002). Foundations in Social Neuroscience. Cambridge: The MIT Press.

Clark, Andy (1997). Being There: Putting Brain, Body, and World Together Again. Cambridge \& London: A Bradford Book, The MIT Press.

(2008). Supersizing the Mind: Embodiment, Action, and Cognitive Extension. Philosophy of Mind. Oxford \& New York: Oxford University Press.

Classen, Constance, ed. (2005). The Book of Touch. Oxford: Berg.

Colzato, Lorenza S., Wery P. M. van den Wildenberg \& Bernhard Hommel (2008). Losing the big picture: How religion may control visual attention. PLoS ONE 3 (11): 1-3.

Cozolino, Louis J. (2002). The Neuroscience of Psychotherapy: Building and Rebuilding the Human Brain. New York \& London: W. W. Norton \& Company.

Csordas, Thomas J. (2002). Body/Meaning/Healing. Basingstoke \& New York: Palgrave Macmillan.

Day, Matthew (2004). Religion, off-line cognition and the extended mind. Journal of Cognition and Culture 4 (1): 101-21.

Deacon, Terrence W. (1997). The Symbolic Species: The Co-Evolution of Language and the Human Brain. London: Allen Lane The Penguin Press.

Dehaene, Stanislas \& Laurent Cohen (2007). Cultural recycling of cortical maps. Neuron 56: 384-98.

Dissanayake, Ellen (1992). Homo Aestheticus: Where Art Comes From and Why. New York: The Free Press, 1992; reprint, Seattle \& London: University of Washington Press, 1999.

- (2000). Art and Intimacy: How the Arts Began. Seattle \& London: University of Washington Press.

Donald, Merlin (1999). The widening gyre: Religion, culture and evolution. Science \& Spirit Magazine 10 (2): 22-23.

- (2001). A Mind So Rare: The Evolution of Human Consciousness. New York \& London: W. W. Norton \& Company, 2001.

Edwards, Derek (1997). Discourse and Cognition. London: SAGE Publications Ltd.

Ellen, Roy (2010). Theories in anthropology and 'anthropological theory'. Journal of the Royal Anthropological Institute (n.s.) 16: 387-404.

Evans, Dylan (2003). Placebo: Mind Over Matter in Modern Medicine. London: HarperCollins Publishers, 2003.

Feierman, Jay R., ed. (2009). The Biology of Religious Behavior: The Evolutionary Origins of Faith and Religion. Santa Barbara, Denver \& Oxford: Praeger.

Frank, Jerome D. (1974). Persuasion and Healing: A Comparative Study of Psychotherapy. Revised Edition. 2nd ed. Schocken Paperbacks on Psychology. Baltimore: The Johns Hopkins University Press, 1961; revised 1974, reprint, New York: Schocken Books, 1977.

Gallagher, H. L., F. Happé, N. Brunswick, P. C. Fletcher, U. Frith \& C. D. Frith (2000). Reading the mind in cartoons and stories: An fMRI study of 'theory of mind' in verbal and nonverbal tasks. Neuropsychologia 38: 11-21.

Gallagher, Helen L. \& Christopher D. Frith (2003). Functional imaging of 'theory of mind'. TRENDS in Cognitive Sciences 7 (2): 77-83.

Gallese, Vittorio (2003). A neuroscientific grasp of concepts: From control to representation. Philosophical Transactions of the Royal Society of London 358: 1231-1240.

Gallese, Vittorio \& George Lakoff (2005). The brain's concepts: The role of the sensory-motor system in conceptual knowledge. Cognitive Neuropsychology 22: 455-479.

Geertz, Armin W. (1999). Definition as analytical strategy in the study of religion. Historical Reflections/Reflexions Historiques 25 (3): 445-75.

- (2004). Cognitive approaches to the study of religion. In New Approaches to the Study of Religion. Volume 2: Textual, Comparative, Sociological, and Cognitive Approaches, edited by Peter Antes, Armin W. Geertz \& Randi R. Warne: 347-399. Berlin: Walter de Gruyter. 
(2008). Religion and cognition: A crisis in the academic study of religion? Bulletin of the Council of Societies for the Study of Religion 37 (4): 91-95.

Geertz, Armin W., ed. (2011). Origins of Religion, Cognition and Culture. London: Equinox Publishing (in press).

Geertz, Armin W. \& Jeppe Sinding Jensen, eds. (2010). Religious Narrative, Cognition and Culture: Image and Word in the Mind of Narrative. London: Equinox Publishing (in press).

Geertz, Clifford (1966). The impact of the concept of culture on the concept of man, [1966], reprinted in Geertz, The Interpretation of Cultures: Selected Essays: 33-54. New York: Basic Books, Inc., 1973.

- (1973). The Interpretation of Cultures: Selected Essays. New York: Basic Books, Inc.

Herman, David, ed. (2003). Narrative Theory and the Cognitive Sciences. Stanford: CSLI Publications, Center for the Study of Language and Information.

Hinde, Robert A. (1998). Mind and artefact: A dialectical perspective. In Cognition and Material Culture: The Archaeology of Symbolic Storage, edited by Colin Renfrew \& Chris Scarre: 175-79. Cambridge: McDonald Institute for Archaeological Research.

Hogan, Patrick Colm (2003). The Mind and Its Stories: Narrative Universals and Human Emotion. Cambridge: Cambridge University Press.

Hrdy, Sarah Blaffer (2009). Mothers and Others: The Evolutionary Origins of Mutual Understanding. Cambridge \& London: The Belknap Press of Harvard University Press.

Humphrey, Nicholas (1986). The Inner Eye, London: Faber and Faber Ltd., 1986; reprint, Oxford: Oxford University Press, 2002.

Hutchins, Edwin (1995). Cognition in the Wild. Cambridge \& London: The MIT Press, 1995; reprint, 2000.

Jensen, Jeppe Sinding (2002). The complex worlds of religion: Connecting cultural and cognitive analysis. In Current Approaches in the Cognitive Science of Religion, edited by Ilkka Pyysiäinen and Veikko Anttonen: 203-28. London \& New York: Continuum.

- (2003). The Study of Religion in a New Key: Theoretical and Philosophical Soundings in the Comparative and General Study of Religion. Aarhus: Aarhus University Press.

(2009). Religion as the unintended product of brain functions in the 'standard cognitive science of religion model': On Pascal Boyer, Religion Explained (2001) and Ilkka Pyysiäinen, How Religion Works (2003). In Contemporary Theories of Religion: A Critical Companion, edited by Michael Stausberg: 129-55. Abingdon \& New York: Routledge.

Johnson, Mark (2007). The Meaning of the Body: Aesthetics of Human Understanding. Chicago \& London: The University of Chicago Press.

Kaptchuk, Ted J. (2002). The placebo effect in alternative medicine: Can the performance of a healing ritual have clinical significance? Annals of Internal Medicine 136 (11): 817-25.

Malafouris, Lambros (2010). The brain-artefact interface (BAI): A challenge for archaeology and cultural neuroscience. Social Cognitive and Affective Neuroscience 5 (2-3): 264-73.

Mareschal, Denis, Mark H. Johnson, Sylvain Sirois, Michael W. Spratling, Michael S. C. Thomas \& Gert Westermann (2007). Neuroconstructivism: Volume One-How the Brain Constructs Cognition. Oxford: Oxford University Press.

Mareschal, Denis, Sylvain Sirois, Gert Westermann \& Mark H. Johnson, eds. (2007). Neuroconstructivism: Volume Two-Perspectives and Prospects. Oxford: Oxford University Press.

Mithen, Steven (1996). The Prehistory of the Mind: A Search for the Origins of Art, Religion and Science. London: Thames and Hudson Ltd., 1996; reprint, London: Phoenix, 1998.

- (1999). Symbolism and the supernatural. In The Evolution of Culture: An Interdisciplinary View, edited by Robin Dunbar, Chris Knight \& Camilla Power: 147-69. New Brunswick: Rugters University Press, 1999, 2nd paperback printing 2003.

Nair, Rukmini Bhaya (2002). Narrative Gravity: Conversation, Cognition, Culture. Oxford \& New Delhi: Oxford University Press.

Neisser, Ulric \& Robyn Fivush, eds. (1994). The Remembering Self: Construction and Accuracy in the Self-Narrative. Cambridge University Press. 
Neisser, Ulric \& David A. Jopling, eds. (1997). The Conceptual Self in Context: Culture, Experience, Self-Understanding. Cambridge: Cambridge University Press.

Niedenthal, Paula M., Lawrence W. Barsalou, Piotr Winkielman, Silvia Krauth-Gruber \& Francois Ric (2005). Embodiment in attitudes, social perception, and emotion. Personality and Social Psychology Review 9 (3): 184-211.

Norman, Donald (1993). Things that Make Us Smart. Reading: Addison-Wesley.

Ochs, Elinor and Lisa Capps (1996). Narrating the self. Annual Review of Anthropology 25: $19-43$.

(2001). Living Narrative: Creating Lives in Everyday Storytelling. Cambridge \& London: Harvard University Press.

Peacock, James L. \& Dorothy C. Holland (1993). The narrated self: Life stories in process. Ethos. Journal of the Society for Psychological Anthropology 21 (4): 367-83.

Petrovic, Predrag, Thomas Dietrich, Peter Fransson, Jesper Andersson, Katrina Carlsson \& Martin Ingvar (2005). Placebo in emotional processing: Induced expectations of anxiety relief activate a generalized modulatory network. Neuron 46: 957-69.

Petrovic, Predrag, Eija Kalso, Karl Magnus Petersson \& Martin Ingvar (2002). Placebo and opioid analgesia: Imaging a shared neuronal network. Science 295: 1737-40.

Plotkin, Henry (2002). The Imagined World Made Real: Towards a Natural Science of Culture. London: Allen Lane, The Penguin Press, 2002.

Raafat, Ramsey M., Nick Chater \& Chris Frith (2009). Herding in humans. TRENDS in Cognitive Sciences 13 (10): 420-28.

Renfrew, Colin (1998). Mind and matter: Cognitive archaeology and external symbolic storage. In Cognition and Material Culture: The Archaeology of Symbolic Storage, edited by Colin Renfrew \& Chris Scarre: 1-6. Cambridge: McDonald Institute for Archaeological Research, 1998.

Renfrew, Colin \& Chris Scarre, eds. (1998). Cognition and Material Culture: The Archaeology of Symbolic Storage. Cambridge: McDonald Institute for Archaeological Research.

Robbins, Philip \& Murat Aydede (2009). A short primer on situated cognition. In The Cambridge Handbook of Situated Cognition, edited by Philip Robbins and Murat Aydede: 3-10. Cambridge et al.: Cambridge University Press.

Roepstorff, Andreas, Chris Frith \& Uta Frith (2009). How our brains build social worlds. New Scientist, 2737: 1-3.

Rosengren, Karl S., Carl N. Johson \& Paul L. Harris, eds. (2000). Imagining the Impossible: Magical, Scientific, and Religious Thinking in Children. Cambridge: Cambridge University Press.

Rowlands, Mark (2003). Externalism: Putting Mind and World Back Together Again. Montreal, Kingston, Ithaca: McGill-Queen's University Press.

Sarbin, Theodore R., ed. (1986). Narrative Psychology: The Storied Nature of Human Conduct. New York, Westport \& London: Praeger Publishers.

Saver, Jeffrey L. \& John Rabin (1997). The neural substrates of religious experience. Journal of Neuropsychiatry and Clinical Neurosciences 9 (3): 498-510.

Schloss, Jeffrey \& Michael J. Murray, eds. (2009). The Believing Primate: Scientific, Philosophical, and Theological Reflections on the Origin of Religion. Oxford \& New York: Oxford University Press.

Seligman, Rebecca \& Ryan A. Brown (2009). Theory and method at the intersection of anthropology and cultural neuroscience. Social Cognitive and Affective Neuroscience (2009): 1-8.

Siegel, Daniel J. (2001). Toward an interpersonal neurobiology of the developing mind: Attachment relationships, "mindsight," and neural integration. Infant Mental Health Journal 22, (1-2): 67-94.

Sinnott-Armstrong, Walter, ed. (2008). Moral Psychology. Volume 1: The Evolution of Morality: Adaptations and Innateness. Volume 2: The Cognitive Science of Morality: Intuition and Diversity. Volume 3: The Neuroscience of Morality: Emotion, Brain Disorders, and Development. Cambridge \& London: The MIT Press. 
Sørensen, Jesper (2004). Religion, evolution, and an immunology of cultural systems. Evolution and Cognition 10 (1): 61-73.

Stausberg, Michael (2009). There is life in the old dog yet: An introduction to contemporary theories of religion. In Contemporary Theories of Religion: A Critical Companion, edited by Michael Stausberg: 1-21. London \& New York: Routledge.

Sterzer, Philipp, Chris Frith \& Predrag Petrovic (2008). Believing is seeing: Expectations alter visual awareness. Current Biology 18 (16): R697-R698.

Vogeley, Kai \& Andreas Roepstorff (2009). Contextualising culture and social cognition. TRENDS in Cognitive Sciences 13 (12): 511-16.

Whitehouse, Harvey \& Luther H. Martin, eds. (2004). Theorizing Religions Past: Archaeology, History, and Cognition. Walnut Creek et al.: AltaMira Press.

Wilson, Margaret (2010). The re-tooled mind: How culture re-engineers cognition. Social Cognitive and Affective Neuroscience 5 (2-3): 180-87.

Yovsi, Relindis Dzeaye (2003). Ethnotheories About Breastfeeding and Mother-Infant Interaction: The Case of Sedentary Nso Farmers and Nomadic Fulani Pastorals with Their Infants 3-6 Months of Age in Mbven Sub Division of the Northwest Province of Cameroon. Münster, Hamburg \& London: LIT Verlag.

Zwaan, R. A. \& L. J. Taylor (2006). Seeing, acting, understanding: Motor resonance in language comprehension. Journal of Experimental Psychology: General 135: 1-11. 